\title{
Sustainable supply chain of the biomass cluster as a factor for preservation and enhancement of forests
}

\author{
Mantas Svazas \\ School of Economics and Business, \\ Kaunas University of Technology, \\ Lithuania \\ mantas.svazas@ktu.edu
}

\section{Valentinas Navickas}

School of Economics and Business,

Kaunas University of Technology,

Lithuania

valentinas.navickas@k.tu.lt

\section{Emilia Krajnakova}

Faculty of Social and Economic Relations, Alexander Dubček. University of Trencín,

Slovakia

emilia.krajnakova@tnuni.sk

Joanna Nakonieczny

Faculty of Management, Rzeszow University of Technology,

Poland

j.nakonieczny@pr..edu.pl

Abstract. The aim of this article has been to investigate the impact of supply chains on sustainable forest development. The results of the research carried out by the authors show that the supply chain ensures more sustainable use of forests and saves lumber from energy production. The article outlines the synergy between supply chain performance and the sustainable use of forest resources. With balanced supply chain processes, it is possible to achieve the sole usage of wood waste and non-productive wood for the production of energy. The authors of the article have compared the data on Lithuanian and Polish border regions and have developed a model for the supply chain effect on orests' preservation. The model demonstrates that supply chain reduces the amount of energy used in energy production and increases the use of wood waste to meet the energy needs of society.

Keywords: cluster, biomass cluster, sustainable supply chain, forests 
JEL Classification: O13, P34, Q56

\section{INTRODUCTION}

Nearly all environmental ideas stem from the desire to preserve nature for future generations and use natural resources in the most sustainable way. It has become an important trend in economic theory, which examines the impact of changing natural environment on the economies of various countries. Environmental impact is inseparable from the energy situation in a country or a region. Srovnalíková, Havierniková, Guščinskiene (2018) and Szegedi, Gabriel, Papp, (2017) demonstrate that concentration of different companies' resources could assist in achieving the goals of sustainable development. The energy sector is undergoing the greatest transformations as compared to other economy sectors and the negative environmental impact of this sector can be minimized. Encouragement for using smaller amounts of fossil fuels can be seen in numerous research works (Andrushkiv et al., 2012). According to Oró et al. (2015), since carbon-based fuels are ending and since they are the primary source of greenhouse gas emissions, more attention should be drawn to renewable energy sources. Global energy consumption trends are already changing. Bala Subrahmanya (2006) noted that energy usage in developing countries has been increasing at a faster rate than in developed countries, a trend that is expected to continue. In order to avoid negative environmental consequences, it is necessary to use more green energy. According to Toklu (2017), biomass energy is derived from plants and animals, such as wood from natural forests, waste from agricultural and forestry processes and industrial, human or animal waste. Currently, biomass is mostly used in the production of green energy. The waste is shredded and used to produce energy. When it comes to forest biomass, it is noticeable that companies operating at this market tend to cluster. The cluster structure saves resources, shares information, and delivers the final product to targeted markets. Efficiency of a cluster is determined by how it manages the supply chain processes. A balanced supply chain is required to meet the environmental requirements. This allows achieving the main objective of cluster activity: energy production from non-recyclable waste. At the same time, it is imperative to have no shortages of biomass in the future. Balancing the supply chain of a biomass cluster allows achieving the maximum positive environmental impact and avoiding complicated situations. One of these, according to Bringes et al. (2012) and Johansson (2013), is when food-producing areas switch to growing energy crops. There are currently no studies on the impact of biomass cluster supply chain, therefore, this phenomenon is poorly investigated in the scientific context. Supply chain models provided by Aulin et al., (2019), Azizi, Mohebbi, \& Azadfallah (2018), Ayoub et al. (2007), Iakovou et al. (2010), Rentizelas et al. (2009), Sharma et al. (2013) assess the environmental aspects but lack explanation on how supply chain contributes to forest preservation. The supply chain ensures that only unusable wood and non-recyclable waste are used to produce energy.

The authors of this article have developed a model for the supply chain effect on forests preservation. The model demonstrates that supply chain reduces the amount of energy used in energy production and increases the use of wood waste to meet the society's energy needs. The authors' research shows that sustainable supply chain of a biomass cluster provides perfect conditions for rational use of forest resources, thus creating conditions for preservation and expansion of forests. Calculations show that having sustainable biomass cluster supply chain prevents biofuel storage at the equivalent of 27 tons of oil. This allows saving 174 cubic meters of live forest per calendar year. It can be said that the results of the research are verified by the fact that they can be used in researching the possibilities of biomass trading of two countries: Lithuania and Poland. 
Literature analysis in this article focuses on two key aspects - supply chain and its influence on forests' preservation. The aim of this article is to investigate the biomass cluster impact on forests' preservation and expansion. Activity of a supply chain could increase the level of sustainable development within the area. This research will focus on the development of biomass energy subsector using the principles of planning. The aim of the article is to fulfill the following objectives: (1) analysis of the possibilities to create a cross-border trade system; (2) to propose measures to assess cross-border trade in biomass; (3) evaluation of trade in biomass between Lithuania and Poland.

\section{LITERATURE REVIEW}

The growth of renewable resources in the world has led to a breakthrough in biomass waste utilization. For a long time, an absolute majority of biomass have been produced solely from forest waste. With the growth of industrial waste and energy crops, the share of forest biomass is decreasing. However, forest waste remains an important part of biomass and the main object of biomass cluster activity. The cluster processes waste generated during felling and arranges for their supply to boiler houses. To meet this goal, an extremely well-balanced supply chain is needed, which can take into account the changes fuel needs, weather conditions and the behavior of fossil fuel users. The concept of the supply chain in this case depends both on the specifics of the biomass cluster and on the structure of the biomass market.

Biomass is used differently, depending on the energy needs of a particular region. Generally, it produces heat energy, but electricity is also extracted from it. There are other alternatives to using biomass. Piriou (2007) states that biomass from wood is considered to be one of the best feedstocks for energy production, for reasons of availability, costs and relative homogeneity. Wood can be seen as an arrangement of organic polymers containing in some extent mineral matter. Biomass (mainly wood) combustion is still largely used all over the world, especially in developing countries, but even though it is cheaper, its thermal efficiency is comparative low. Meanwhile biomass gas extraction is becoming increasingly popular. Biomass gasification is accepted as one of the best solutions for biomass conversion, since the process can be easily down scaled and allow a good control of the products distribution. The main solution for classifying primary products is the ability to demonstrate the production of energy in different ways.

Lately, efforts to increase energetic stability in the countries, reflect the inevitability of the biomass cluster's activities. The prevailing fluctuating economic and geopolitical situation in different parts of the world makes it necessary to seek solutions that reduce the impact of fossil fuel imports on the country's energy needs. When questioning the energetic security, renewable energy plays a vital role (Štreimikienè et al., 2016; Rade et al., 2019). According to Glăvan, B. (2008), clusters arise because companies are stimulated to locate near one another to take advantage of the existence of a variety of external effects. The basic reason for clustering is the minimization of transportation and communication costs. Also, geographical proximity gives companies the possibility to access a large pool of suppliers (including skilled workforce) and thus reduce search costs, which positively impacts productivity. In addition, industrial agglomeration facilitates the flow of tacit knowledge among firms. This is particularly favorable in the biomass sector, where cooperation is essential for cutting costs. From an economic, social and environmental perspective, one of the best substitutes for fossil fuels is biomass. It can provide stable energy supply and ensure balance, regardless of the natural conditions prevailing at that time. However, replacing fossil fuels with biomass requires not only substantial investments, but also a sustainable structure for the newly emerging sector of biomass energy.

Cluster's activity is inseparable from the principles of sustainable development. do Carmo Farinha, de Matos Ferreira, Gouveia (2014) believes that competitiveness creates the basic conditions for sustainable 
development and growth, new production activities, jobs, and better quality of life. McCauley, Stephens (2012) also support this idea claiming that sustainable energy cluster initiatives aim to stimulate local and regional economic development by creating the conditions that attract and promote innovative firms in the area of sustainable, renewables-based energy. According to Figge, Hahn (2004), in order to commercially utilize the advantages of sustainable development methodology, it should be included to corporate governance guidelines. It is necessary to consider how enterprise activities change the level of natural, human and social capital. It is directly applicable to the biomass cluster, as it affects all these factors. Gomes, Muylaert de Araujo (2009), Streimikiene et al. (2019) adds that bio-fuels made from waste biomass or from biomass grown on abandoned agricultural lands planted with perennials incur little or no carbon debt and offer immediate and sustained GHG advantages.

The structure of the biomass energy sector is determined by the specifics of the emergence and development of biomass. The economic result is related to the natural processes that generate biomass resources. Different natural processes create different types of biomass that can be used to generate heat, electricity or biogas. Business structure is formed based on biomass type and its emergence and its key objective are biomass conversion to energy and financial gain.

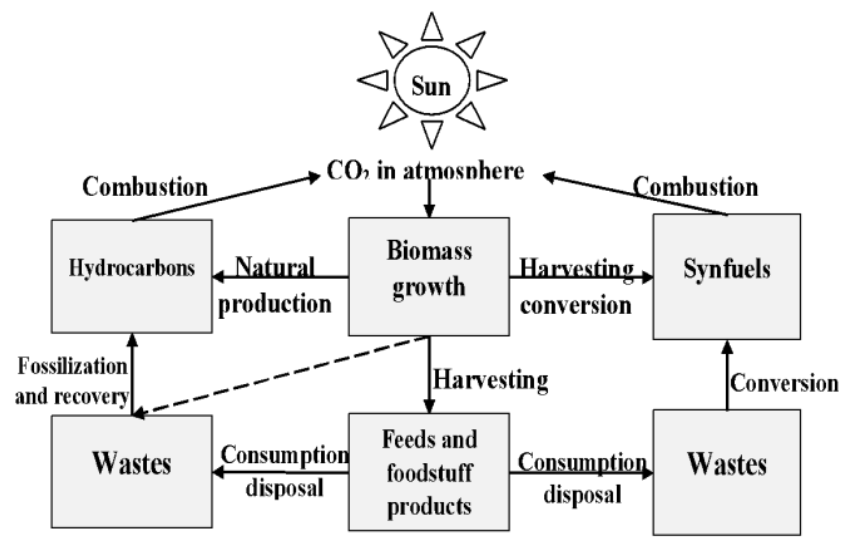

Figure 1. Key aspects of biomass energetics

Source: Ellabban, et al. (2014), Havrysh et al.(2019)

Key biomass energy attributes described in Fig. 1 indicate two types of biomass production: naturally growing plants and energy crops harvested periodically. The resulting waste is used to produce other products, while the biomass energy business meets the basic principles of circular economy. It is precisely the circular economy that creates sense for the development of biomass energy business. It allows for the preservation of the forests and their expansion.

According to Galik (2015), Simionescu et al. (2017) bioenergy market participation, defined here as "the direct generation of earnings from bioenergy market activities", maybe observed differently across different parts of the bioenergy market supply chain. Specifically, market participation will mean different things for biomass producers, energy producers, and brokers, processers, and other intermediaries. Therefore, the relations and priorities among the participants in a biomass energy structure may vary in the context of changed circumstances or the situation of enterprises. Structural sector changes can be influenced by the specifics of the region's activity and the types of fuel prevailing there. It is possible to bring resources from other regions or even states to geographic areas that lack biomass resources. The regions however should not be substantially distanced to prevent the increase in fuel prices.

There is also a necessity for biomass to be transported over longer distances, even from other continents, because the modern use of biomass is increasing rapidly in many parts of the world. It can be 
applied to certain types of biomass that allows achieving the benefits provided by the economies of scale. The principal scheme of such decision is given in Fig. 2.

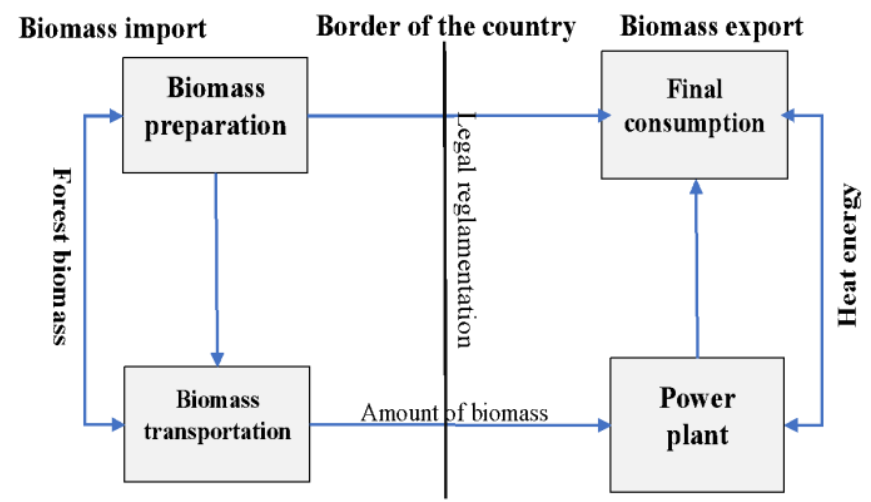

Figure 2. Cross-border biomass trading

Source: Created by authors

This model is particularly applicable when a foreign region has more biomass resources which are cheaper than biomass in the local region. The model can be used for the development of biomass trading in the border regions of Lithuania and Poland. Therefore, it contributes to the conservation and enhancement of the wider ecosystem, as forest waste resources between countries are used more efficiently and more economically. At the same time, synergistic effects appear: reduced transportation costs, lower environmental pollution by exhaust gas, boiler houses acquire fuel faster. However, a supply chain that includes entities involved in the preparation, transport and use of biomass is required for this purpose. The supply chain would also contribute to the preservation of forests as it regulates how and when resources are used for a given biomass resource.

\section{METHODOLOGY}

Seeking to investigate the impact of the supply chain on forest conservation, a typical example of the region is used. In the smaller regions, smaller power plants, which able to adapt quickly to the needs of consumers are predominant. The storage capacity is abandoned, and the supply of biomass is constantly coordinated with the suppliers. The delivery is carried out from three different deposits that are not evenly distant from the power plant. It is also estimated how much biomass would be lost if the just-in-time mode was replaced with the storing at outdoor sites regime.

In this case the aim is to evaluate the meaning for different countries to market biofuels, regardless of national borders. That would allow each country to utilize available resources at the same time reducing environmental pollution and to achieve synergistic effects through cooperation. Table 1 provides general case data assessing biofuel resources and power plants available in a mid-level region. Calculations do not take into account storage capabilities seeking to avoid possible loss of fuel caused by adverse weather conditions and excessive storage. Daily biomass demand is expressed in tons of oil equivalent (TOE) meanwhile, in normal case, the size is equal to the capacity of two trucks. The aim is to partially show the rationality of such a solution in economic and sustainable development terms. The choice of biofuel price is based on the average annual data of the energy resource exchange BALTPOOL. 
Research conditions of the supply chain impact on forest preservation and expansion

\begin{tabular}{|l|c|}
\hline \multicolumn{1}{|c|}{ Condition } & Meaning \\
\hline Distances between biomass bodies and the power plant & $10 \mathrm{~km} ; 20 \mathrm{~km} ; 35 \mathrm{~km}$. \\
\hline Capability of the powerplant & $5 \mathrm{MW}$ \\
\hline Number of customers & 1000 \\
\hline Truck's capacity & $5 \mathrm{TOE}$ \\
\hline Daily biomass demand & $3650 \mathrm{TOE}$ \\
\hline Annual biomass demand & just-in-time (JIT) \\
\hline Storage regime & $5 \%$ \\
\hline Annual biomass growth & $150 \mathrm{EUR}$ \\
\hline Estimated biomass price & $1,5 \%$ per 4 months \\
\hline Biomass rate of decay while storing & $1825 \mathrm{TOE}$ \\
\hline Available amount for storage & \\
\hline
\end{tabular}

Source: Own evaluation

Following the provided data authors are researching ways to assess the efficiency of the supply chain. Supply chain application optimizes costs and is environmentally beneficial. The abandonment of storage capacity alone can save $4.5 \%$ of wood resources. Calculation formulas take into account the amount of saved biomass, the economic impact of this phenomenon as well as the performance results of specific supply chain. The use of trucks is assessed as it is the most efficient means of transportation for short distances. The reduction in transportation costs is directly related to the environmental improvements, therefor it is an important evaluation aspect not only from economical point of view.

The next step evaluates the overall financial savings generated by the supply chain. They are derived from the estimates of avoidable biomass losses and the prevailing market price of biomass. As the remains of biomass are left in the forest, we can avoid transportation costs that affect the efficiency of the supply chain. Although the required quantity for storage is being transported for 2 to 3 months, the decay processes occur near the base of the biomass. Burning the last of biomass reserves shows that a certain amount of biomass is no longer suitable for energy production. It forms the additional costs associated with the removal of waste biomass from the boiler-house. All formulas created by authors. Seasonal biomass savings are calculated according to the formula:

$$
S B S=S B^{*} L
$$

SBS - biomass seasonal savings, TOE; SB - amount of biomass in storage, TOE; L - loss, $\%$

The existing biomass savings also require the prevailing cost of biomass and transportation costs that are no longer necessary to be spent on transporting part of biomass. The savings in the supply chain enable cluster members to return funds to the forests, using them for the expansion and maintenance of the forest. Supply chain performance improvements with the refuel of storage are presented in the formula:

$$
S C S=S B S^{*} P+S B S^{*} T C
$$

SCS - supply chain savings; P - biomass price, EUR/TOE; TC - biomass transportation costs, EUR

To obtain the value of the formula, it is necessary to not only have the necessary data but also to calculate the exact savings in transportation costs. That way, the exact amount of biomass saved can be 
estimated, and the figure is expressed in the amount of trucks. Since biomass is transported from multiple places, the effect of biomass savings is transferred to all biomass areas. All this is estimated at the prevailing fuel prices of that time. Total transportation costs can be calculated using the following formula:

$$
T C=T D P^{*} F C
$$

TDP - total distance between points, $\mathrm{km}$.; FC - fuel costs, EUR/km

Using the JIT concept, biomass that has not been treated not necessarily remains in the forests. Without biomass processing costs, it may be targeted at other cluster activities. It has been estimated that wood can grow by about $5 \%$ per year. The amount of biomass saved next year is supplemented by natural growth, which adds additional environmental and economic value. With less productive wood resources, unpolluted biomass can grow for a longer period. The growth of biomass, which contributes to the intensification of forest resources, is estimated by the formula:

$$
B G=S B S^{*} A F G
$$

$\mathrm{BG}$ - biomass growth, toe; $\mathrm{AFG}$ - annual average biomass growth, $\%$

In order to facilitate the assessment of the amount of biomass stored, growth, expressed in tons of oil equivalent, can be converted to cubic meters. The conversion value depends on the type of biomass, humidity, and other factors. An important factor is the age of the wood, as well as the time elapsed between cutting and processing. In this case, one ton of oil equivalent is considered to be 6.0625 cubic meters of wood.

When assessing the impact of cross-border trade in biomass, it is considered that cross-border regions can provide biomass for each other more effectively. The change in biomass between border regions ensures that the balanced biomass amount will be used and forestry will be guaranteed. This is especially true for Lithuania and Poland, since fossil fuel is used extensively in these countries. The effect of border trade on biomass is calculated using the formula:

$$
B T B=D F I * F C-D F O * F C
$$

BTB - border trade of biomass, EUR; DFI - distance to the forest inside the country, km.; FC - fuel cost, EUR/km.; DFO - distance to the forest outside the country

The result shows the impact of using foreign forest resources. Lesser distance to biomass location from a foreign region reduces the overall costs of biomass transportation, which increases the competitiveness of the biomass cluster's supply chain and makes the use of local resources more sensible. The impact is reflected in the difference between domestic and external trade, showing how much outside trade can reduce overall supply costs.

\section{EMPIRICAL RESULTS AND DISCUSSION}

The supply chain is one of the key elements of the cluster's activity, which ensures product competitiveness and satisfaction of consumers needs. At the same time, this is one of the key ways to improve the cluster activity efficiency. Bringing together different processes of the supply chain reveals the common challenges that the cluster must deal with. Supply chain planning requires a variety of analysis that allows recycling, transportation and incineration plans to be made. As the cluster's activities focus on 
supplying in real time, activities of increased precision and planning are required. Dealing with blocks of individual processes allows to proceed to the final planning of supply chain, which, at the same time, contributes to forest conservation.

The transportation of biomass in relation to fossil fuels is much more complicated. In order to generate energy efficiently, biomass deposits are required to be close to the plant. Also, depending on their types, appropriate vehicles are needed to transport biomass. Yue et al. (2014) argues that from an operational point of view, the biomass is cost-prohibitive and unstable for long-distance transport because of slow energy density and high-water content. In the modelling practice, a circle around the biomass supplier is often specified as the feasible region for building biomass processing facilities, of which the radius equals to the "feasible distance" for raw biomass transportation. Murphy et al. (2014) have shown in their research that transport as the most energy and greenhouse gas emissions intensive step in the life cycle. This finding illustrates importance of localized production and use of forest biomass.

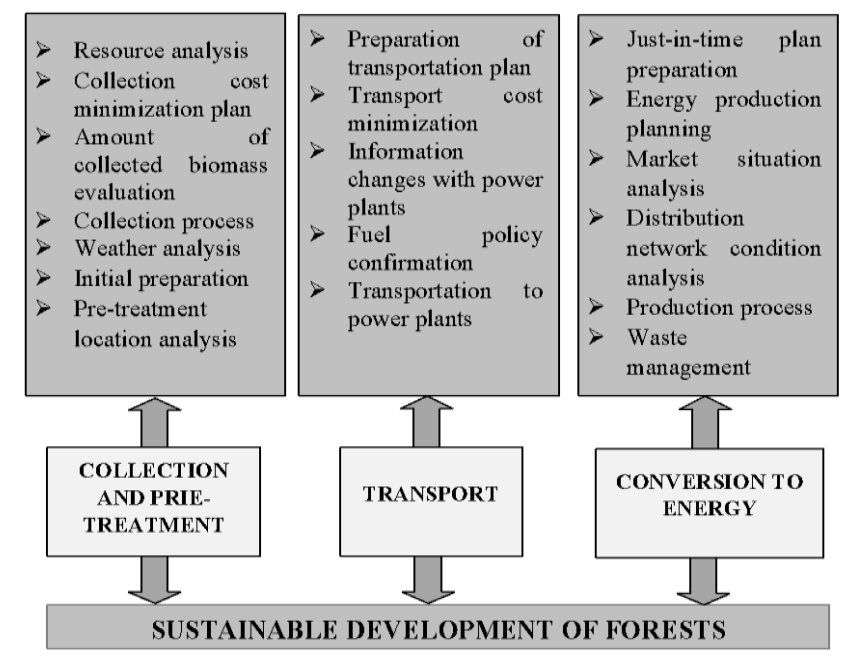

Figure 3. Model of sustainable forest development

Source: own evaluation

Each supply chain process has additional functions that at the same time are planning objects. This can improve the supply chain balance and allow a higher response rate. The maintained sequence of actions is one of the key components of successful supply chain. According to Figure 3, there are three supply chain processes that form separate supply chain balancing steps. The figure shows that the storage capacity is not included. The biomass cluster is based on just-in-time philosophy and real-time provision. This way, forest resources are saved because they are not decaying in storage. Production based on the actual needs of the power plant ensures that biomass resources are not wasted, the productivity is improved and contribution to the conservation of forests will be made.

When analyzing individual supply chain balancing actions, it is noticeable that they can be divided into one-offs and continuous ones. One-off actions are usually carried out at the initial stage of the supply chain formation, while continuing operations are carried out by setting a certain benchmark period. These steps help to maintain consistent supply chain efficiency. It mainly applies to extraction and transportation processes, as these processes are significantly influenced by external factors. According to Kishore, Bhandari, Gupta (2004), organization's supply chain would require the following inputs for steady, profit making operation:

- Quality technical and R\&D inputs from established institutes; 
- A high level of system integration to optimize operations.

- Mechanisms to ensure supply of biomass and sale of power and other goods and services.

- Financing schemes at low interest rates both for initial and working capitals.

In the analysis of supply chain processes, the amount of resources needed to prepare biomass per unit of transportation is important. The size of the resource depends on the area of the deposit, its availability, and the type of wood. Significant impact on efficiency is given by the novelty of energy and the balance of processes. Sharma et al. (2013) and Kot et al., (2017) believe that supply chain management focuses on integration of all entities such that the end-product is produced and distributed in the right quantity, at the right time, to the right location, providing desired quality, and service level along with minimizing the overall cost of the system. Cost minimization contributes to the conservation of forest resources. Having a production plan and choosing how to process biomass, allows to avoid the use of surplus production and the use of productive wood for burning.

In the supply chain (Fig. 4), all biomass energy market participants and the processes between them are included. Excluded are the two flows: financial and information. This chain can be applied to regions supply: their activity area is up to $100 \mathrm{~km}$. Considering this distance is included for the main market participants, the amount can be different, it depends on regions size.

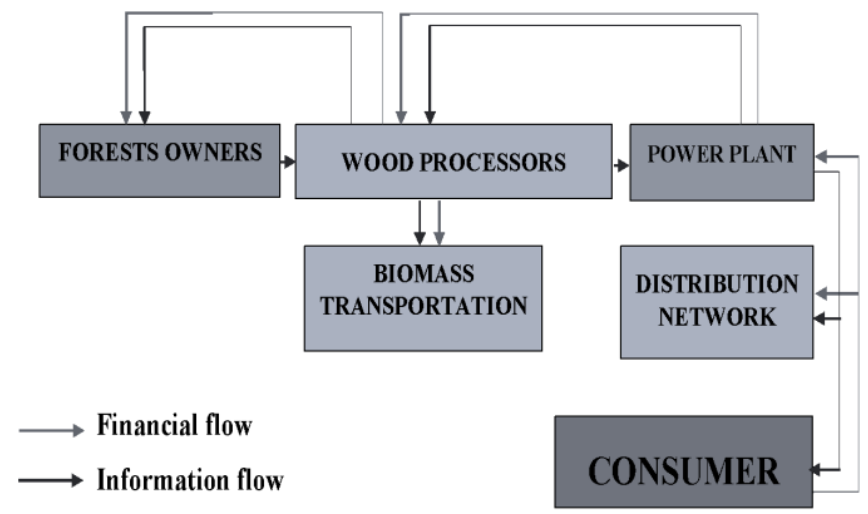

Figure 4. Model of supply chain effect on forest preservation

Source: own evaluation

The biomass energy supply chain is specific, because both the information and financial flow can move in several ways. The main reason for this phenomenon is the number of intermediates. In the chain there are three main subjects: biomass owners, power plants and consumers. Especially important intermediate is wood processors, which closely communicate both purchase and sales ranges. Control of power plants can have both government and private business, meanwhile control of distribution networks is largely owned by government. Consumers can quickly determine the price of waste and processors and the optimization of transportation work. By Anderson and Fergusson (2006), in the energy crops case, the costs of transporting raw biomass materials may have a significant impact on overall crop economics, thus limiting the distance over which biomass can be economically transported between source and end-use locations.

This supply chain describes the entire biomass sector - it is decentralized and includes more market participants. When ensuring stable biomass supply and optimizing processes, energy price is competitive. However, the supply chain can also contribute to forest conservation and cross-border cooperation. By balancing the supply chain, less forests will be used, thus allowing the further growth. 
Data presented in Table 1 is used to calculate the quantitative effect of the supply chain. Firstly, the biomass savings are evaluated during the heating season. The savings, just like all other indicators, are expressed in tons of oil equivalent. Biomass savings over the season are presented using the formula (1).

$$
S B S=1825 * 1,5 \%=27,375
$$

The calculated indicator is important for the calculation of other formulas. One of the most important indicators is the supply chain savings, as illustrates the efficiency of supply chain in financial terms. The biomass equivalent is priced at 150 EUR, which is the prevailing price in Lithuania and Poland. At the same time, the eliminated transportation costs are estimated. The financial efficiency of the supply chain is calculated using the following formula (2).

$$
S C S=27,375 * 150+27,375 * 104,65=6971,04
$$

Transportation costs are needed to assess the supply chain savings. The amount that was received and expressed in TOE was converted to the number of trucks (6 trucks in this particular case). The distance $(260 \mathrm{~km})$ was obtained by dividing two trucks of biomass for each place, considering the distance to and from. Fuel consumption for $100 \mathrm{~km}$ is considered to be 35 liters and the price of diesel is 1.15 euros. That way we get fuel consumption per kilometer. Transport costs are calculated below.

$$
T C=260 * 0,4025=104,65
$$

While assessing forest preservation opportunities, the average increment of wood is used. Since one ton of oil equivalent is 6.0625 cubic meters of wood, the indicator is converted. The indicator is obtained by evaluating the part of the wood that would be lost in case of storing. The balanced supply chain of the biomass cluster allows that forest part to remain untouched, continue to grow and form a beneficial effect on the forest ecosystem. The results are obtained using the formula (4):

$$
B G=27,375 * 5 \%=28,74375 * 6,0625=174,259
$$

In the case of cross-border biomass trading, it is considered that the distance to the forest within the country is $50 \mathrm{~km}$ and the distance to the forest outside the country is $15 \mathrm{~km}$. We use the previously calculated fuel consumption per kilometer. Looking at parts of the formula shows what positive effects can be achieved by exchanging the biomass between different regions while optimizing the supply distances. It also shows how to reduce biomass transport costs by importing biomass from foreign regions in close proximity. To get the result, the formula (5) is applied:

$$
B T B=50 * 0,4025-15 * 0,4025=14,09
$$

In conclusion, the biomass cluster supply chain generates financial benefits for its members and contributes to the sustainable use and enhancement of forests. The supply chain allows to avoid the meaningless process of wood processing into biomass when it is soaked. That particular biomass has transportation costs, thus we reduce fuel costs by reducing biomass production. The survival of biomass continues to grow and it will mature over the next year, and at the same time, financially more expensive. Collaboration with foreign countries can provide synergies in the preservation and enhancement of biomass as biomass supply is coordinated among several regions.

\section{CONCLUSION}

This study has shown that the biomass cluster supply chain can contribute to the preservation and enhancement of forests. The biomass structure allows it to be used to produce different types of energy, thus achieving better waste recovery. At the same time, exists the conditions for cross-border trade on biomass, as this can help reduce the consumption of biomass, air pollution, transportation and storage 
costs. Expansion of green energy consumption ideas emphasizes sustainable development. The use of biomass waste makes it possible not to lose natural resources and at the same time protect forests using biological waste - branches, bark, stumps. The efficiency of biomass usage is increased when all processes are developed in a cluster structure that unites biomass supply, transportation, and utilization entities.

The research methodology is based on the principles of cross-border trade and the pursuit of maximum resource savings. The development of cross-border trade rationalizes the usage of available resources, reduces transport costs, avoids costly storage solutions, since in a significant loss of biomass. The article examines the example of Lithuania and Poland. Lithuania has redirected its energy system towards biomass over a decade, while Poland needs to increase the use of renewable energy sources to reduce its share of coal in the energy system. Research formulas are focused on clarifying the situation and showing that the growth of biomass use can provide one of the founding principles of the European Union - the production of clean energy from renewable sources.

Using the supply chain, you can avoid the storage process, thus using biomass resources more efficiently. Analysis has shown that sustainable development of forests consists of collection and pretreatment, transport and conversion processes. This corresponds with the main processes of a balanced supply chain and allows to achieve the goal of preserving forests. The supply chain helps reducing transportation and storage costs when real-time production is guaranteed. Since wood waste is used in the production of biomass, it prevents the combustion of productive wood. The supply chain allows crossborder trade in biomass: border regions can obtain biomass by reducing supply distances and expediting biomass delivery times. This is relevant to Lithuania and Poland, as the countries are reducing the use of fossil fuels and rely more heavily on biomass. The cross-border impacts of trade in biomass and supply chain savings are indicated by the formula in the article. They are based on a typical scheme prevailing in the regional areas of both countries. The application of the formulas allows obtaining results related to saving biomass and increasing the level of forest conservation. At the same time, it is proved that there are possible preconditions for the existence of cross-border trade biomass agreements. This way, synergies between countries are achieved through more efficient use of biomass resources and reduced transport costs, air pollution, and administrative costs.

\section{ACKNOWLEDGEMENT}

This research was supported by the project VEGA agency no. 1/0953/16

\section{REFERENCES}

Anderson, G.Q.A., \& Fergusson, M.J. (2006). Energy from biomass in the UK: sources, processes and biodiversity implications. Ibis, 148, 180-183.

Andrushkiv, B. M., Vovk, Y. Y., \& Vovk, I. P. (2012). Resursonomika: teoretychni ta prykladni aspekty [Resourcenomy: theoretical and applied aspects]. Ternohraf, Ternopil, Ukraine.

Aulin, V., Lyashuk, O., Pavlenko, O., Velykodnyi, D., Hrynkiv, A., Lysenko, S., Vovk, Y., \& Sokol, M. (2019). Realization of the Logistic Approach in the International Cargo Delivery System. Communications-Scientific letters of the University of Zilina, 21(2), 3-12.

Ayoub, N., Martins, R., Wang, K., Seki, H., \& Naka, Y. (2007). Two levels decision system for efficient planning and implementation of bioenergy production. Energy Conversion and Management, 48(3), 709-723.

Azizi, M., Mohebbi, N., \& Azadfallah, M. (2018). Determining effective criteria on sustainable development of fluting paper making industry. Economics, Management and Sustainability, 3(2), 20-28.

Bala Subrahmanya, M.H. (2006). Labour productivity, energy intensity and economic performance in small enterprises: A study of brick enterprises cluster in India. Energy Conversion and Management, 47, 763-777. 
Baltpool. (2019). Biomass spot price. Retrieved from https://www.baltpool.eu/en/biomass-spot-price/

Bringezu, S., O’Brien, M., \& Schütz, H. (2012). Beyond biofuels: Assessing global land use for domestic consumption of biomass: A conceptual and empirical contribution to sustainable management of global resources. Land Use Policy, 29(1), 224-232.

do Carmo Farinha, L. M., de Matos Ferreira, J. J., \& Gouveia, J. J. B. (2014). Innovation and Competitiveness: A High-Tech Cluster Approach. Romanian Review Precision Mechanics, Optics \& Mechatronics, 45, 41-48.

Ellabban, O., Abu-Rub, H., \& Blaabjerg, F. (2014). Renewable energy resources: Current status, future prospects and their enabling technology. Renewable and Sustainable Energy Reviews, 39, 748-764.

Figge, F., \& Hahn, T. (2004). Sustainable value added-measuring corporate contributions to sustainability beyond eco-efficiency. Ecological Economics, 48(2), 173-187.

Galik, C.S. (2015). Exploring the determinants of emerging bioenergy market participation. Renewable and Sustainable Energy Reviews, 47, 107-116.

Glăvan, B. (2008). Coordination failures, cluster theory, and entrepreneurship: a critical view. The Quarterly Journal of Austrian Economics, 11(1), 43-59.

Gomes, M.S.P., \& Muylaert de Araujo, M.S. (2009). Bio-fuels production and the environmental indicators. Renewable and Sustainable Energy Reviews, 13, 2201-2204.

Havrysh, V., Nitsenko, V., Bilan, Y., \& Streimikiene, D. (2019). Assessment of optimal location for a centralized biogas upgrading facility. Energy and Environment, 30(3), 462-480. doi:10.1177/0958305X18793110

Iakovou, E., Karagiannidis, A., Vlachos, D., Toka, A., Malamakis, A. (2010). Waste biomass-to-energy supply chain management: a critical synthesis. Waste management, 30(10), 1860-1870.

Johansson, B. (2013). Security aspects of future renewable energy systems - A short overview. Energy, 61, 598-605.

Kot, S., Onyusheva, I., \& Grondys, K. (2018). Supply Chain Management in SMEs: Evidence from Poland and Kazakhstan. Engineering Management in Production and Services, 10 (3), 23-36

McCauley, S.M., \& Stephens, J.C. (2012). Green energy clusters and socio-technical transitions: analysis of a sustainable energy cluster for regional economic development in Central Massachusetts, USA. Sustainability Science, 7, 213-225.

Murphy, F., Devlin, G., \& McDonnell, K. (2014). Forest biomass supply chains in Ireland: A life cycle assessment of GHG emissions and primary energy balances. Applied Energy, 116, 1-8.

Oró, E., Depoorter, V., Garcia, A., \& Salom, J. (2015). Energy efficiency and renewable energy integration in data centres. Strategies and modelling review. Renewable and Sustainable Energy Reviews, 42, 429-445.

Piriou, B. (2007). Catalytically assisted gasification of biomass. [in:] Proceeding of 30th meeting on Combustion of the Italian Section of the Combustion Institute, Istituto di Ricerche sulla Combustione, Napoli, Italy.

Rabe, M., Streimikiene, D., \& Bilan, Y. (2019). The Concept of risk and possibilities of application of mathematical methods in supporting decision making for sustainable energy development. Sustainability, 11(4), 1018.

Rentizelas, A.A., Tolis, A.J., \& Tatsiopoulos, I.P. (2009). Logistics issues of biomass: The storage problem and the multi-biomass supply chain. Renewable and Sustainable Energy Reviews, 13(4), 887-894.

Sharma, B., Ingalls, R.G., Jones, C.L., \& Khanchi, A. (2013). Biomass supply chain design and analysis: basis, overview, modeling, challenges, and future. Renewable and Sustainable Energy Reviews, 24, 608-627.

Simionescu, M., Albu, L. L., Raileanu Szeles, M., \& Bilan, Y. (2017). The impact of biofuels utilisation in transport on the sustainable development in the European Union. Technological and Economic Development of Economy, 23(4), 667-686.

Srovnalíková, P., Havierniková, K., \& Guščinskiene, J. (2018). Assessment of reasons for being engaged in clusters in terms of sustainable development. Journal of Security and Sustainability Issues, 8(1), 103-112.

Streimikiene, D., Simionescu, M., \& Bilan, Y. (2019). The Impact of Biodiesel Consumption by Transport on Economic Growth in the European Union. Engineering Economics, 30(1), 50-58. 
Štreimikiené, D., Strielkowski, W., Bilan, Y., \& Mikalauskas, I. (2016). Energy dependency and sustainable regional development in the Baltic States: A review. Geographica Pannonica, 20(2), 79-87.

Szegedi, Z., Gabriel, M., \& Papp, I. (2017). Green supply chain awareness in the hungarian automotive industry. Polish Journal of Management Studies, 16(1), 259-268.

Toklu, E. (2017). Biomass energy potential and utilization in Turkey. Renewable Energy, 107, 235-244.

Yue, D., You, F., \& Snyder, S.W. (2014). Biomass-to-bioenergy and biofuel supply chain optimization: overview, key issues and challenges. Computers \& Chemical Engineering, 66, 36-56. 